\title{
Caracterização Mecânica e Microestrutural da Zona de Transição do Aço 9\% Ni Revestido com Inconel $625^{\circ}$
}

Cleber do Prado Ferreira Junior ${ }^{1}$ (D), Antonio do Nascimento Silva Alves $^{1}$ (D), Jeferson José de Carvalho ${ }^{1}$ (D), Jaime Casanova ${ }^{2}$, Sérgio Duarte Brandi ${ }^{1}$ (D)

${ }^{1}$ Universidade de São Paulo - USP, Escola Politécnica, Departamento de Engenharia Metalúrgica e de Materiais, São Paulo, SP, Brasil.

${ }^{2}$ Universidade Federal do Amazonas - UFAM, Faculdade de Tecnologia, Departamento de Engenharia de Materiais, Manaus, AM, Brasil.

Como citar: Ferreira Junior CP, Alves ANS, Carvalho JJ, Casanova J, Brandi SD. Caracterização mecânica e microestrutural da zona de transição do aço $9 \%$ Ni revestido com Inconel 625 ${ }^{\circledR}$. Soldagem \& Inspeção. 2021;26:e2604. https://doi.org/10.1590/0104-9224/SI26.04

Resumo: Aços carbono são revestidos com Inconel $625^{\circ}$ para atender os requisitos de projeto no Pré-Sal. Entretanto, isso gera microrregiões conhecidas como a zona não misturada (ZNM) e a zona parcialmente misturada (ZPM) sendo a sua formação relacionada a dissimilaridade entre o metal de base e o metal de adição. O objetivo desse artigo é analisar o efeito da diluição, da ZPM e da ZNM e do reaquecimento dessas microrregiões sobre a resistência ao arrancamento do aço $9 \%$ Ni revestido com a liga Inconel $625^{\circ}$. A ZNM tem direções cristalográficas similares a ZAC e é CCC igual a ZAC. A ZPM apresenta direções cristalográficas mais heterogêneas quando comparadas ao metal de solda e é CFC igual ao metal de solda. A nanodureza da ZPM é similar a ZAC e até $42,5 \%$ maior que o metal de solda. A nanodureza da ZNM é até $14,9 \%$ menor que ZPM, até $48,2 \%$ menor que o metal de solda e até $15 \%$ menor que a ZAC. Todos os corpos de prova tiveram a propagação da trinca no metal de solda e atendem o requisito de $140 \mathrm{MPa}$ mínimo para a tensão de cisalhamento. A diluição apresenta uma correlação com a tensão de cisalhamento.

Palavras-chave: Aço 9\% Ni; Inconel $625^{\circ}$; Zona não misturada; Zona parcialmente misturada; Revestimento.

\section{Microstructural and Mechanical Characterization of the Transition Zone of $9 \% \mathrm{Ni}$ Steel coated with Inconel $625^{\circ}$}

\begin{abstract}
Carbon steels are coated with Inconel $625^{\circ}$ to comply the pre-salt project requirements. However, this generates micro-regions such as the unmixed zone (UMZ) and a partially mixed zone (PMZ), with the formation related to the dissimilarity between the base metal and the addition metal. The purpose of this article is the analyze of the effect of dilution, PMZ and UMZ and the reheating of these micro-regions on the pullout resistance of $9 \% \mathrm{Ni}$ steel coated with the Inconel $625^{\circledR}$ alloy. The UMZ has similar crystallographic directions to the heat affected zone (HAZ) and is BCC equal to HAZ. The PMZ presents more heterogeneous crystallographic directions when compared to the weld metal and is FCC equal to the weld metal. The PMZ nano-hardness is similar to HAZ and up to $42.5 \%$ greater than the weld metal. UMZ's nano-hardness is up to $14.9 \%$ less than PMZ, up to $48.2 \%$ less than weld metal and up to $15 \%$ less than HAZ. All specimens had crack propagation in the weld metal and comply the requirement of $140 \mathrm{MPa}$ minimum for shear stress. The dilution presents a correlation with the shear stress.
\end{abstract}

Key-words: 9\% Ni Steel, Inconel 625 ; Unmixed Zone; Partially Mixed Zone; Coating.

\section{Introdução}

Os aços ligados ao níquel são aplicados em condições de temperaturas abaixo de $0{ }^{\circ} \mathrm{C}$. Entre os diversos tipos de aços ligados ao Ni destaca-se o aço com $9 \% \mathrm{Ni}$. A sua aplicação é comum em reservatórios de gás natural liquefeito, onde é submetido à temperatura de $-162^{\circ} \mathrm{C}$, exigindo do material alta resistência mecânica e tenacidade a fratura em temperaturas criogênicas (abaixo de $-153^{\circ} \mathrm{C}$ ) $[1,2]$. $\mathrm{O}$ aço $9 \% \mathrm{Ni}$ vem sendo usado para substituir os aços de alta resistência e baixa liga no atendimento da demanda de exploração de gás e petróleo no Pré-Sal brasileiro [3-5]. Entre as diversas aplicações desse aço, destaca-se o uso em tubulações de transporte de produtos derivados de petróleo resistentes à corrosão nos módulos das plataformas FPSO [3]. Contudo, por ter seu uso classificado como restrito em condições com $\mathrm{H}_{2} \mathrm{~S}$ pela norma ISO 15156 [6,7], a solução para o uso desse aço é o revestimento com superligas de níquel, como o Inconel $625^{\circ}$ (NiCrMo-3) $[4,8]$.

A aplicação por meio de soldagem da liga NiCrMo-3 apresenta excelente custo/benefício, visto que o material é utilizado apenas em regiões de interesse [9]. Seu elevado percentual de Ni, $\mathrm{Cr}$ e Mo atribui uma excelente resistência à corrosão. Todavia, a sua aplicação no revestimento de aços carbono por processos de soldagem a arco elétrico, pode reduzir a resistência à corrosão 
da liga devido à alta diluição com o metal de base, o que pode aumentar a quantidade do elemento químico ferro acima de $5 \%$ wt na superfície do revestimento [10,11].

O revestimento do aço $9 \% \mathrm{Ni}$ com a liga Inconel $625^{\circ}$, por meio de um processo de soldagem a arco elétrico, gera a fusão tanto do metal de base (MB), como do metal de adição, para formar o metal de solda (MS). A combinação desses dois materiais diferentes pode causar a formação de microrregiões com composição química, microestrutura e propriedade mecânica diferentes do metal de base (MB) e do metal de solda (MS). Sendo identificadas como zona parcialmente misturada (ZPM) e zona não misturada (ZNM), podendo ainda serem subclassificadas em ilhas, baias e praias [9,12-20].

A ZPM e a ZNM são formadas pela mistura hidrodinâmica entre o MB e o metal de adição, podendo ou não ter diferentes composições químicas. Separado por um gradiente de difusão da zona não misturada, onde uma pequena porção do MB fundi totalmente e solidifica sem sofrer diluição do metal de adição. A borda externa da zona não misturada limita uma região parcialmente misturada na interface de solda. Essas microrregiões ainda podem ser influenciadas pelas temperaturas liquidus do MS e do MB, com possível influência das velocidades de resfriamento que cada microrregiões sofre, sendo localizadas no MS [9,12-21]. De acordo com a literatura, as zonas parcialmente misturadas podem falhar quando submetidas à esforços de tensões [9]. As diferenças microestruturais nessas microrregiões podem ter cristalografias diferentes entre si, com concentrações de tensões mais elevadas, com propriedades mecânicas diferentes e tornando-se caminhos preferências para propagação de trincas [22].

Assim, o objetivo desse artigo é analisar o efeito da diluição, da ZPM e da ZNM e do reaquecimento dessas microrregiões sobre a resistência ao arrancamento do aço $9 \%$ Ni revestido com a liga Inconel $625^{\circ}$.

\section{Materiais e Métodos}

O metal de base utilizado nos experimentos para revestimento por soldagem foi o aço comercial ASTM A553 Tipo I com $9 \%$ de níquel. Sua composição química e propriedades mecânicas estão apresentadas na Tabela 1 e na Tabela 2 . Esse material foi tratado termicamente com têmpera, têmpera intercrítica e revenimento, esses tratamentos térmicos são oriundos do fabricante da chapa. As dimensões da chapa eram de 300,0 mm de largura, 500,0 mm de comprimento e 11,0 mm de espessura. O metal de adição utilizado foi um arame maciço ER NiCrMo-3, comercialmente conhecido como Inconel $625^{\circ}$, com diâmetro de 1,14 mm e composição química descrita na Tabela 3.

O processo de soldagem utilizado para realizar o revestimento da chapa de aço com $9 \%$ Ni foi o TIG em corrente contínua e polaridade direta (-). A alimentação do arame foi automática com velocidade média de alimentação de $186 \mathrm{~cm} / \mathrm{min}$, com ângulo de entrada do arame de $18^{\circ}$ em relação a face da chapa e na temperatura ambiente (arame frio). A temperatura ambiente foi adota como temperatura interpasse. A tocha foi posicionada a $90^{\circ}$ em relação a face da chapa. Utilizou-se o argônio como gás de proteção com vazão de $18 \mathrm{~L} / \mathrm{min}$. O ângulo de afiação do eletrodo de tungstênio $\left(2 \%\right.$ de $\left.\mathrm{ThO}_{2}\right)$ foi de $60^{\circ}$ e os parâmetros de soldagem estão mostrados na Tabela 4, sendo obtidos através de um sistema de aquisição de dados. A polaridade direta foi preterida por ser amplamente utilizada na temática de revestimento, onde aços carbono são revestidos com ligas de níquel $[4,8]$.

Tabela 1. Composição química do aço ASTM A553 Tipo I utilizado. Valores em porcentagem em massa.

\begin{tabular}{ccccccc}
$\mathbf{C}$ & $\mathbf{M n}$ & Si & P & S & Ni & \\
0,08 & 0,73 & 0,35 & 0,006 & 0,003 & 9,40 & 0,002 \\
\hline
\end{tabular}

Nota: *Técnica de combustão (Leco ${ }^{*}$. Outros elementos via espectrometria de emissão óptica.

Tabela 2. Propriedades mecânicas do aço ASTM A553 Tipo I utilizado como metal de base. Valores fornecidos pelo fabricante.

\begin{tabular}{ccc} 
Propriedade Mecânica & Longitudinal a Laminação & Transversal a Laminação \\
Limite de Escoamento (MPa) & 665 & 781 \\
Limite de Resistência (MPa) & 737 \\
Alongamento (\%) & 28,7 \\
Charpy (J) @- $196^{\circ} \mathrm{C}(10 \times 7,5)$ & $174^{*}$ & $181^{*}$ \\
\hline
\end{tabular}

Nota: Tamanho das amostras Charpy são reduzidas segundo a norma ASTM A370. *Valores médios.

A soldagem ocorreu na posição plana, foram realizados três cordões de solda um ao lado do outro com diferentes comprimentos, Figura 1. O comprimento diferente dos cordões de solda foi adotado para poder verificar a possível influência 
que os ciclos térmicos de soldagem apresentariam sobre o cordão de solda já realizado. A altura de cada cordão de solda foi de aproximadamente $2,5 \mathrm{~mm}$. O local de remoção de cada corpo de prova está representado na Figura 1.

Tabela 3. Composição química do metal de adição ER NiCrMo-3 utilizado. Valores fornecidos pelo fabricante em porcentagem em massa.

\begin{tabular}{cccccccccc}
\hline $\mathbf{N i}$ & $\mathbf{C r}$ & Mo & Al & $\mathbf{P}$ & $\mathbf{S}$ & $\mathbf{C}$ & $\mathbf{N b}+\mathrm{Ta}$ & $\mathrm{Fe}$ \\
65,30 & 21,57 & 8,62 & 0,29 & 0,005 & 0,001 & 0,014 & 3,68 & 0,16 \\
\hline
\end{tabular}

Tabela 4. Parâmetros de soldagem médios utilizados na soldagem dos corpos de prova e monitorados com o sistema de aquisição de dados de soldagem.

\begin{tabular}{|c|c|c|c|c|}
\hline Cordão de Solda & Tensão (V) & Corrente (A) & $\begin{array}{l}\text { Velocidade de Soldagem } \\
\qquad(\mathrm{mm} / \mathrm{s})\end{array}$ & Energia de Soldagem $(\mathrm{kJ} / \mathrm{mm})$ \\
\hline 1 & 22,21 & 221,37 & 2,5 & 0,78 \\
\hline 2 & 20,36 & 221,63 & 2,5 & 0,72 \\
\hline 3 & $*$ & $*$ & 2,5 & $*$ \\
\hline
\end{tabular}

Nota: $\left({ }^{*}\right)$ Os parâmetros do terceiro cordão de solda não foram obtidos por motivos técnicos. Porém, os parâmetros de soldagem não foram alterados quando comparado aos demais cordões já realizados. A eficiência de transmissão de energia adotada para o processo TIG foi de 0,4 [23].

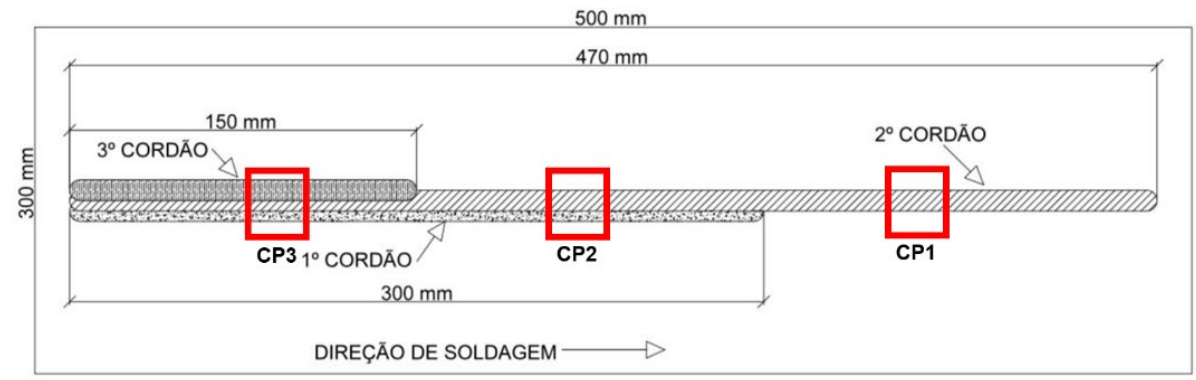

Figura 1. Vista superior da chapa soldada. Dimensões do metal de base, comprimento dos cordões de solda e local de retida dos corpos de prova de cada experimento (CP1-apresenta um cordão de solda; CP2-apresenta dois cordões de solda; e CP3-apresenta três cordões de solda).

\subsection{Ensaios realizados}

A caracterização microestrutural óptica foi executada utilizando o reagente Nital com $2 \%$ de concentração para revelar a microestrutura da ZAC nos corpos de prova. O cálculo de diluição foi realizado por meio da sobreposição dos cordões de solda das macrografias feitas por uma lupa estereográfica e com auxílio do software Axio Vision ${ }^{\circledR}$. A diluição do CP2 foi calculada somente no segundo cordão de solda e no CP3 somente no terceiro cordão de solda. Com o valor da diluição apenas do primeiro cordão de solda (CP1), somente do segundo cordão de solda (CP2) e somente do terceiro cordão de solda (CP3), foi possível medir a influência da execução de cada cordão de solda sobre o primeiro cordão de solda. A partir dos valores de diluição foi calculado a composição química teórica de cordão de solda.

A caracterização por microscopia eletrônica de varredura utilizou um equipamento com sensor de EDS e de EBSD. Todas as análises microestruturais foram realizadas na transição entre a zona afetada pelo calor (ZAC) e o metal de solda (MS) do primeiro cordão de solda. Na mesma região onde foi realizada a análise via EDS, também foi realizado o ensaio de penetração instrumentada (nanodureza). As imagens de MEV não apresentam a mesma magnitude que as análise de EDS. As linhas de EDS foram realizadas entre duas marcas de microdureza e com as superfícies das amostras polidas.

O ensaio de penetração instrumentada foi realizado em um triboindentador com cargas de $2 \mathrm{mN}$, usando um penetrador de diamante tipo Berkovich. A força total do ensaio foi aplicada com uma permanência de 2 s e o carregamento e o descarregamento da força teve $5 \mathrm{~s}$ em cada etapa. Estes tempos são padronizados no laboratório onde foi realizado o ensaio. Todas as medidas sempre foram realizadas na transição entre a ZAC e o MS do primeiro cordão de solda. Assim como na análise microestrutural, o ensaio de penetração instrumentada também foi realizado na transição entre a ZAC e o MS do primeiro cordão de solda. 
Os mapas de nanodureza sempre foram realizadas na transição entre a ZAC e o MS do primeiro cordão de solda em todas as amostras. Cada mapa de nanodureza contém 90 impressões com um espaçamento mínimo de $3 \mu \mathrm{m}$ entre impressões, dependendo do tamanho da amostra o espaçamento foi aumentado a fim de garantir uma distância máxima entre impressões chegando até $11,6 \mu \mathrm{m}$. Os valores na escala Vickers foram obtidos por meio da conversão da escala GPa para Vickers, segundo a norma ISO 14577-1.

Para o ensaio de cisalhamento foi desenvolvido um dispositivo seguindo os critérios da norma ASTM A263 com as dimensões adaptadas para o ensaio das amostras revestidas por soldagem. O cisalhamento foi realizado por meio de ensaio de compressão com uso de uma máquina de ensaios de tração universal, adotando-se velocidade de avanço de 7,0 mm/min. As amostras foram preparadas por meio de corte de precisão, lixamento das regiões que ficaram em contato com as paredes do dispositivo, visando diminuir ao máximo a dispersão de energia em função do atrito do corpo de prova contra o dispositivo.

\section{Resultados e Discussão}

\subsection{Caracterização microestrutural}

As macrografias, Figura 2, não apresentam nenhum indício de defeitos de soldagem. A partir dessas imagens foi calculada a diluição de cada corpo de prova, sendo o valor da diluição do CP2 e CP3 proporcional ao segundo e ao terceiro cordão de solda. O CP1 apresenta uma diluição de $29,0 \%$ com apenas um cordão de solda, o CP2 (dois cordões de solda) apresenta $12,0 \%$ de diluição e o CP3 (três cordões de solda) apresenta uma diluição de 11,4\%. Esses valores de diluição alteram a composição química global do cordão de solda. Possivelmente, o CP1 apresenta o maior valor de diluição devido os demais cordões de solda (CP2 e CP3) terem uma sobreposição com o primeiro cordão de solda.

A Tabela 5 apresenta a composição química teórica calculada a partir dos valores da diluição de cada corpo de prova. 0 limite máximo do elemento químico ferro adotado foi de $5 \%$ em massa, isso foi baseado na norma API 6A. Nota-se que o limite máximo de ferro é ultrapassado em $421 \%$ para o CP1, em 117\% para o CP2 e 106\% para o CP3, isso ocorre devido aos grandes valores de diluição. Teoricamente, podem comprometer a resistência à corrosão do revestimento. Os elementos químicos Ni, $\mathrm{Cr}$ e Mo tem uma redução em suas frações no metal de solda devido aos altos valores de diluição.
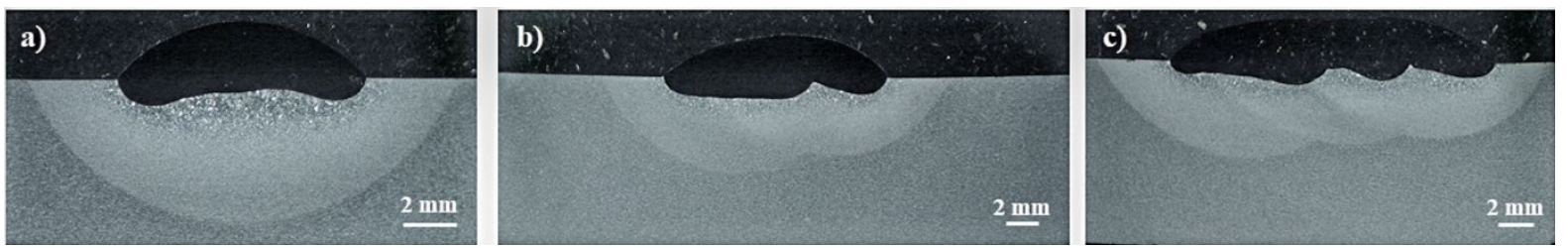

Figura 2. Macrografia dos experimentos. (a) CP1 com um cordão de solda; (b) CP2 com dois cordões de solda; (c) CP3 com três cordões de solda.

Tabela 5. Comparação da composição química teórica do metal de solda calculada para cada corpo de prova em função da diluição. Valores da composição química estão em porcentagem mássica.

\begin{tabular}{ccccccc}
\hline Experimento & Diluição (\%) & $\mathbf{N i}$ & Cr & Mo & Fe \\
Metal de Adição* & - & 65,30 & 21,57 & 8,62 & 0,16 & 26,05 \\
CP1 & 29,0 & 49,07 & 15,31 & 6,12 & 7,64 & 10,86 \\
CP2 & 12,0 & 58,59 & 19,11 & 19,11 & 7,64 & 10,33 \\
CP3 & 11,4 & 58,93 & & \\
\hline
\end{tabular}

Nota: *Valores iguais aos apresentados na Tabela 3.

A ZAC do primeiro cordão de solda (CP1) apresenta pacotes de martensita e um crescimento de grão característico para o aço com $9 \%$ Ni soldado, Figura 3. Após o reaquecimento da ZAC do primeiro cordão pelo segundo cordão de solda (CP2), ainda é possível identificar grandes colônias de bainita (seta em azul), as linhas de microssegregação do metal de base (setas em amarelo) e uma redução e transformação dos pacotes de martensita na ZAC do primeiro cordão de solda. Após o segundo reaquecimento causado pelo terceiro cordão de solda (CP3), a ZAC apresenta uma microestrutura mais refinada quando comparado aos demais corpos de prova e as linhas de microssegregação do metal de base, possivelmente oriunda do processo de laminação da chapa (setas em amarelo), ainda são possíveis de serem observadas na ZAC do primeiro cordão de solda [3,24]. 
O primeiro cordão de solda do CP2 não apresenta indícios da zona não misturada (ZNM) e possui uma zona parcialmente misturada (ZPM - indicada pela seta preta), Figura 4b. O primeiro cordão de solda do CP3 apresenta uma ZPM (indicada pela seta preta) com menor dimensão quando comparada ao CP2. O CP3 também possui uma zona não misturada (ZNM - indicada pela seta branca) no primeiro cordão de solda, Figura 4c.

Não é possível identificar a zona parcialmente misturada (ZPM) e a zona não misturada (ZNM) no CP1. Ressalta-se que foram analisadas três amostras extraídas de diferentes posições com objetivo de identificar essa microrregião no CP1. Contudo, não pode-se afirmar que essas microrregiões não são formadas no CP1, apenas pelo fato de não serem possíveis de identificação (Figura 4a), pois a formação da ZPM e da ZNM é relacionada a diferença de composição química entre o metal de base e o metal de adição, o fato de tais microrregiões não terem sido identificadas no CP1 pode estar relacionada ao movimento da poça de fusão ter conseguido completa fusão da ZPM e da ZNM. Assim como também não é possível afirmar, que a formação dessas microrregiões no CP2 e no CP3 está diretamente relacionada aos ciclos térmicos dos demais cordões de solda, devido ainda não haver registros na literatura que ciclos térmicos de outros cordões de solda possam transformar o metal de solda em ZPM e a ZNM $[9,25]$.

Os mapas de EBSD foram realizados na região de transição entre a ZAC e o metal de solda (MS) da amostra CP3 (três cordões de solda), essa amostra foi escolhida por apresentar a zona parcialmente misturada (ZPM) e a zona não misturada (ZNM) e serem facilmente localizadas. Nota-se na Figura 5a que a ZNM indicada pela seta preta I, localizada no metal de solda, apresenta uma multiplicidade nas direções cristalográficas similar a ZAC e diferente do restante do MS. Essa mesma região (seta preta I) no mapa da Figura $5 b$ é identificada com estrutura cristalina cúbica de corpo centrada, similar a ZAC e diferente do MS. Todavia, a estrutura cristalina da zona parcialmente misturada indicada pela seta preta II, também posicionada no metal de solda, tem direções cristalográficas menos heterogêneas quando comparada com a ZAC e mais heterogêneas quando comparadas ao MS. Quando a ZPM da seta preta Il é analisada no mapa da Figura 5b, nota-se que está possui a mesma estrutura cristalina que o restante do metal de solda (cúbica de face centrada) e é diferente da ZAC. A diferença de cristalografia dessas microrregiões pode gerar concentrações de tensões tornando-se caminhos preferências para propagação de trincas [22].
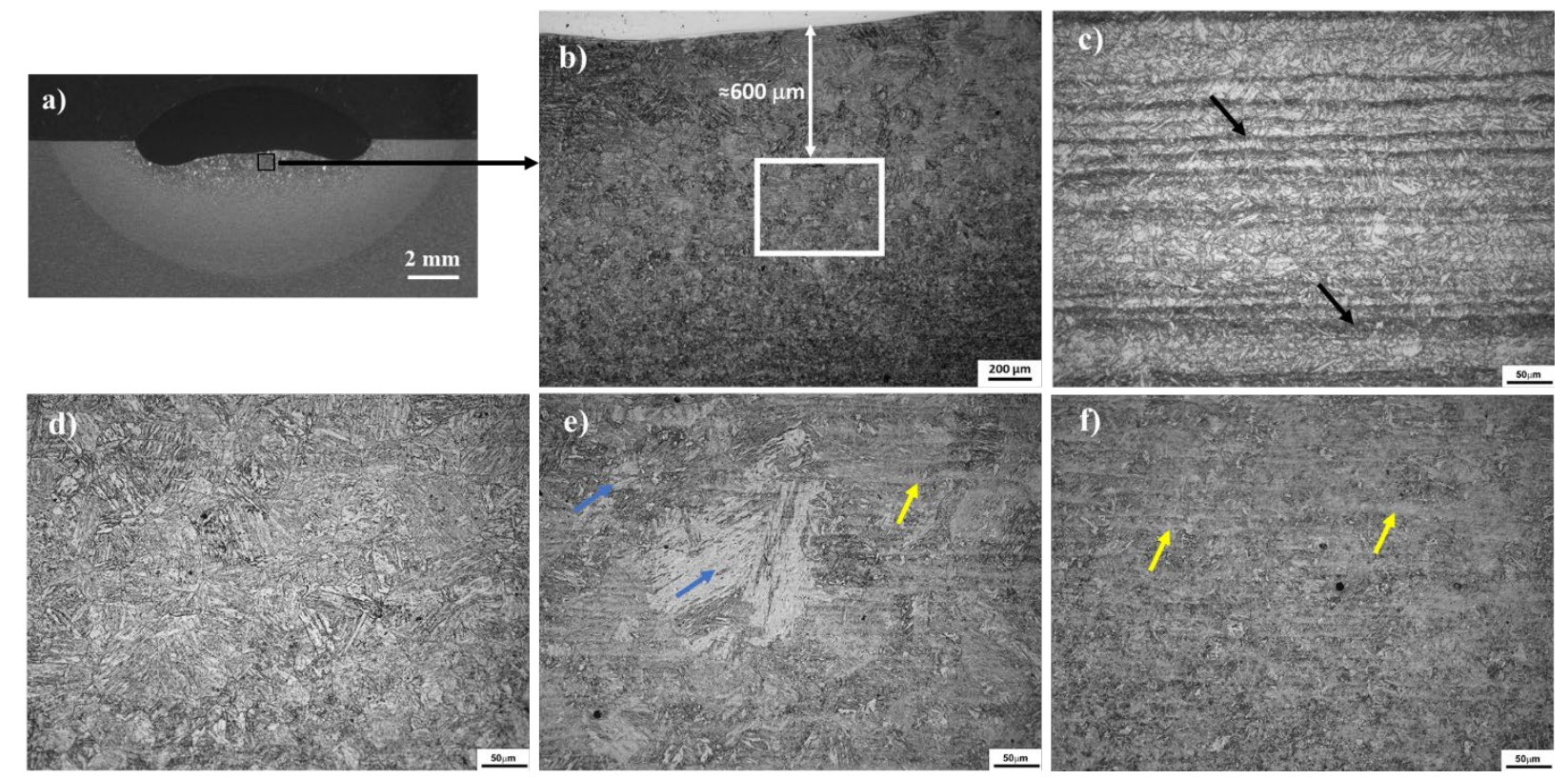

Figura 3. (a) e (b) esquema indicando o posicionamento da aquisição das micrografias das ZACs de cada amostra; (c) microestrutura do metal e base composta por martensita e bainita e em setas em preto linhas de microssegregação. Microestrutura da zona afetada pelo calor dos corpos de prova: (d) CP1-com um cordão de solda com contornos de grão delineados e os pacotes de martensita; (e) ZAC do primeiro cordão de solda reaquecida pelo segundo cordão de solda (CP2-com dois cordões de solda), grandes colônias de bainita e um refino na matriz martensítica; e (f) ZAC do primeiro cordão de solda reaquecida por dois cordões de solda (CP3-com três cordões de solda), microestrutura refinada pelo reaquecimento causado pelos demais passes e linhas de microssegregação em amarelo.

Os resultados da microanálise química (Figura 6a) para o metal de solda do CP1, indicam que os valores do elemento químico ferro variam de $60 \%$ (quanto mais próximo da linha de fusão) até aproximadamente $30 \%$ (quanto mais distante da linha de fusão). Os elementos químicos $\mathrm{Ni}, \mathrm{Cr}$ e Mo apresentam uma concentração inversamente proporcional quando comparados ao elemento químico ferro. 

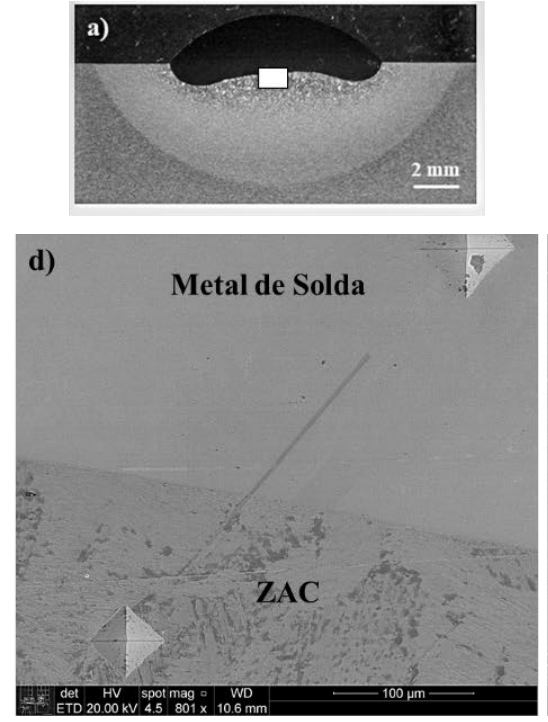

Figura 4. Microestrutura da transição entre a ZAC e o metal de solda. (a) posicionamento do local onde foi realizado a análise do CP1; (b) posicionamento do local onde foi realizado a análise do CP2; (c) posicionamento do local onde foi realizado a análise do CP3; (d) CP1-com um cordão de solda; (e) CP2-com dois cordões de solda, a seta preta indica a zona parcialmente misturada (ZPM); (f) CP3-com três cordões de solda, a seta preta indica a zona parcialmente misturada (ZPM) e a seta branca a zona não misturada (ZNM).
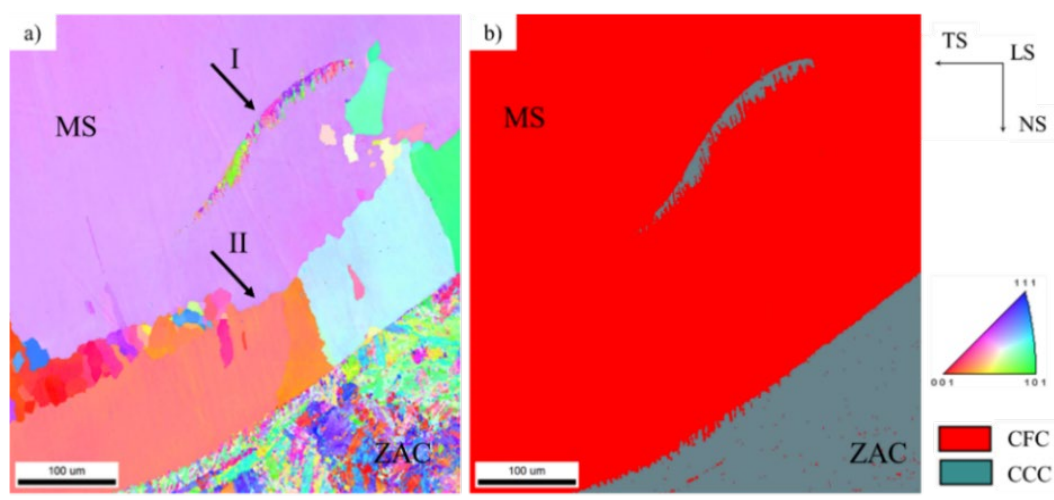

Figura 5. Análise microestrutural via EBSD da transição entre a ZAC e o metal de solda do primeiro cordão do CP3. Step size de 1,0 $\mu \mathrm{m}$. (a) figura de polo inversa; (b) mapa de fase (vermelho fase CFC [austenítica] e cinza fase CCC). MS - metal de solda; ZAC - zona afetada pelo calor; Seta preta I - zona não misturada e seta preta II zona parcialmente misturada.

A amostra CP2 (dois cordões de solda) apresenta a zona parcialmente misturada (ZPM) com aproximadamente $30 \mu \mathrm{m}$ de extensão e com valores do elemento químico ferro que chegam a ultrapassar $80 \%$, Figura $6 \mathrm{~b}$. Conforme a análise se afasta da ZPM, os valores do elemento químico ferro são reduzidos para aproximadamente $50 \%$. Os elementos químicos $\mathrm{Ni}$, Cr e $\mathrm{Mo}$ apresentam uma concentração inversamente proporcional quando comparados ao elemento químico ferro.

Nota-se na Figura 6c o local onde foram realizadas as linhas de microanálise química via EDS sobreposta pelo mapa de EBSD. A microanálise química da Figura 6c-1 mesmo estando fora na área onde foi realizado a análise de EBSD, apresenta uma zona parcialmente misturada (ZPM) com valores do elemento químico Fe próximo de $80 \%$. Ao se afastar da ZPM, os valores do elemento químico ferro tendem a cair para valores próximos de $30 \%$. Esse comportamento é seguido de um aumento dos valores dos elementos químicos $\mathrm{Ni}, \mathrm{Cr}$ e Mo no metal de solda. Ressalta-se que os valores indicados na Figura 6 e na Tabela 6 não estão na superfície do revestimento. Desta forma não é possível afirmar se irão comprometer a resistência à corrosão do revestimento.

As linhas de microanálise química das Figura 6c-2 e Figura 6c-3 apresentam duas zonas parcialmente misturadas (ZPM) e uma zona não misturada (ZNM) em cada mapa. Nessas regiões (ZPM e ZNM) há um acréscimo da concentração do elemento químico ferro e uma redução da concentração dos elementos químicos Ni, Cr e Mo quando comparadas ao metal de solda (MS). Tais regiões coincidem com às áreas identificadas nos mapas de EBSD (Figura 5) como ZPM e ZNM.

A partir dos dados utilizados para montar os gráficos da Figura 6, foi realizado uma média da composição química de cada região identificada (metal de solda, zona não misturada, zona parcialmente misturada e ZAC) e esses resultados são descritos na Tabela 6. Observa-se que a zona parcialmente misturada (ZPM) tem entre 75 e $87 \%$ e a única zona não misturada (ZNM) identificada tem $87 \%$ do elemento químico ferro. A ZPM e a ZNM apresentam similaridade na quantidade de Fe, fazendo com 
que não seja possível separar essas regiões somente analisando esse elemento químico. Todavia, essas microrregiões apresentam diferenças nos valores de $\mathrm{Ni}, \mathrm{Fe}, \mathrm{Cr}$ e Mo quando comparadas ao metal de solda e no caso da ZNM, pode-se afirmar que a identificação dessa microrregião via análise de imagem no MEV e análise de EBSD vem a corroborar tais diferenças e similaridade. A exceção fica para o CP1* que não apresenta similaridade com os demais resultados da ZPM, da ZNM e da ZAC, sendo mais parecido com o metal de solda.

Com relação ao Ni, a ZPM tem valores entre 10 e 17\% e a ZNM apresenta valores entre 8 e $10 \%$. Nesse caso os valores de $\mathrm{Ni}$ da ZNM estão muito mais próximos da ZAC que os valores da ZPM. Os valores de Cr e Mo vão tender a serem maiores na ZPM quando comparados a ZNM. Assim, a ZNM vai ficar com uma composição química mais próxima da ZAC quando comparada com a ZPM, que terá uma composição química mais similar ao metal de solda.

O metal de solda ainda apresenta baixa quantidade do elemento químico Ni e alta fração de Fe devido essa região ainda está muito próxima da ZAC e ter bastante influência do efeito de diluição do metal de base. Ressalta-se que não é levado em consideração os valores calculados de diluição na microanálise química da Tabela 6.

A zona parcialmente misturada (ZPM) e a zona não misturada (ZNM) tem diferentes composições químicas que alteram a temperatura liquidus em microrregiões entre o metal de base (maior temperatura) e o metal de solda (menor temperatura). A diferença da temperatura liquidus entre as regiões analisadas também pode alterar localmente a movimentação da poça de fusão, podendo gerar regiões solidificadas antes que ocorra a mistura com o restante do metal de solda [21].
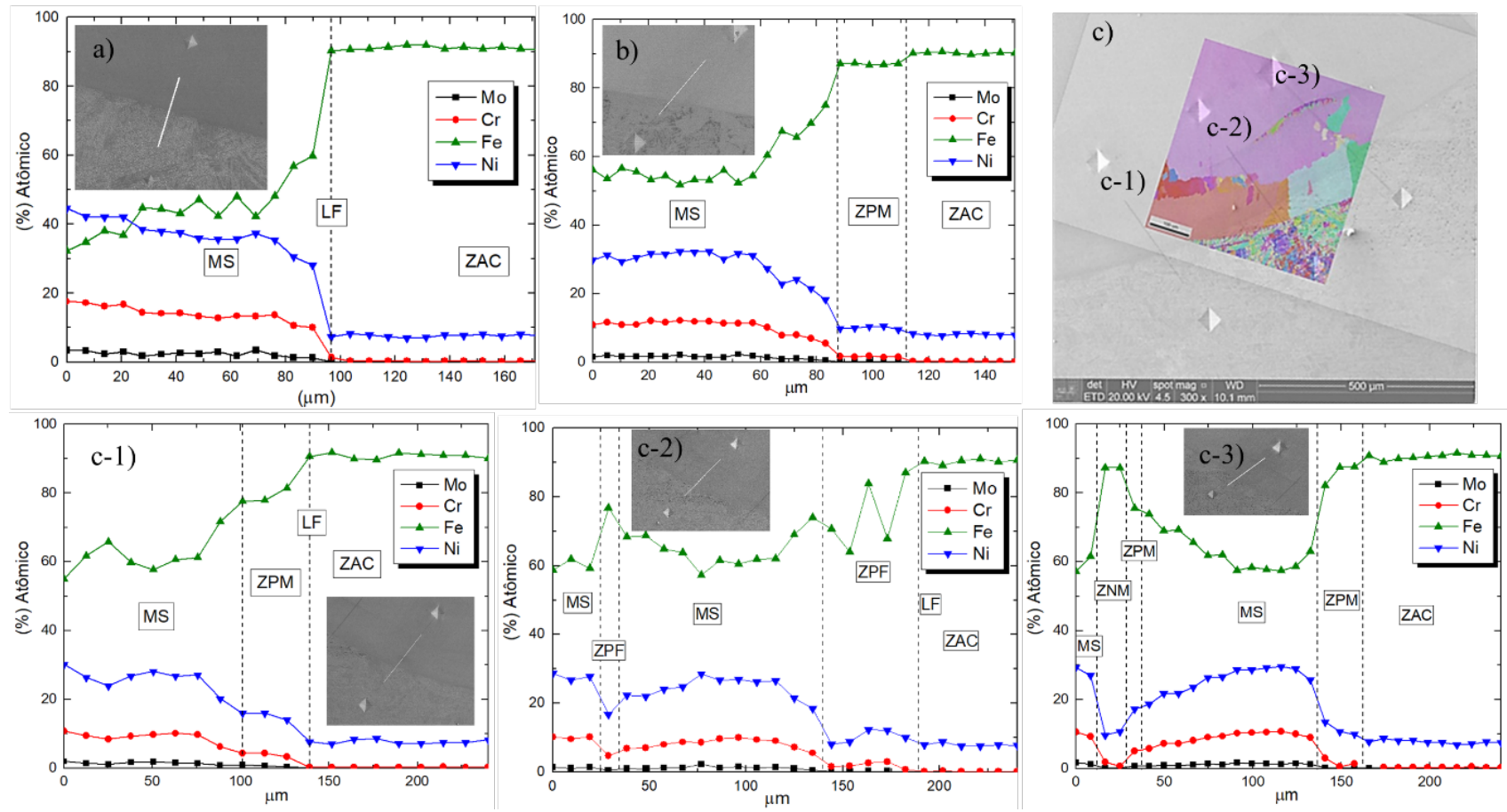

Figura 6. Microanálises química via EDS na transição da ZAC e o metal de solda. (a) linha de microanálise química via EDS do CP1 (um cordão de solda); (b) linha de microanálise química via EDS do CP2 (dois cordões de solda); (c) relação entre a região analisada via EBSD e as linhas de microanálise química do CP3 (três cordões de solda); (c-1), (c-2) e (c-3) são os resultados das respectivas linhas das microanálises química. MS - metal de solda; ZPM - zona parcialmente misturada; ZNM - zona não misturada; LF - linha de fusão; ZAC - zona afetada pelo calor.

\subsection{Ensaio de penetração instrumentada (Nanodureza)}

$\mathrm{Na}$ amostra CP1 (um cordão de solda) os maiores valores de nanodureza estão localizados na ZAC, Figura 7a. Conforme se analisa os valores obtidos no metal de solda, nota-se uma redução desses valores quando comparados a ZAC. O metal de solda apresenta uma nanodureza de 323,5 HV e a ZAC apresenta 425,2 HV. As regiões com os maiores valores de nanodureza no metal de solda, podem estar relacionadas à regiões com uma maior concentração de precipitados de $\mathrm{Nb}$ e Ti e ou a possíveis regiões endurecidas por solução sólida com uma concentração maior do elemento químico Ni. [8].

A nanodureza da ZAC do CP2 (dois cordões de solda), Figura 7b, tem um valor 6,5\% (452,9 HV) maior quando comparada com a ZAC do CP1 e o metal de solda (277,3 HV) é 14,3\% menor quando comparado ao CP1. No mapa "I" (Figura 7c) a nanodureza da ZAC $(369,7$ HV) é $13 \%$ menor que a ZAC do CP1 e 18\% maior quando comparado a ZAC do CP2. A nanodureza do metal de solda do CP3 (249,5 HV) é 22,9\% menor que o CP1 e $10 \%$ menor que o CP2. A zona parcialmente misturada possui nanodureza média de 360,5 HV, sendo similar a nanodureza da ZAC e 44,5\% maior que o metal de solda. 
Tabela 6. Composição química média de cada região identificada na junta soldada das amostras via microanálise química EDS a partir dos dados da Figura 6. Os valores da ZNM (zona não misturada) só são apresentados na análise do gráfico C-3 do CP3. As colunas C-2 e C-3 se repetem com resultados diferentes devido os respectivos mapas na Figura 6 apresentarem mais de uma região com a zona parcialmente misturada.

\begin{tabular}{|c|c|c|c|c|c|c|c|c|c|c|c|c|c|c|c|c|c|c|}
\hline \multirow{2}{*}{ 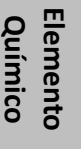 } & \multirow[b]{2}{*}{ CP1 } & \multicolumn{3}{|c|}{ Metal de Solda } & \multirow[b]{2}{*}{ C-3 } & \multicolumn{7}{|c|}{ Zona Parcialmente Misturada } & \multirow{2}{*}{$\begin{array}{c}\text { ZNM } \\
\text { C-3 }\end{array}$} & \multicolumn{5}{|c|}{ Zona Afetada Pelo Calor } \\
\hline & & CP2 & C-1 & C-2 & & CP1* & $\mathrm{CP2}$ & C-1 & $C-2^{1}$ & $C-2^{2}$ & $C-3^{1}$ & $C-3^{2}$ & & CP1 & CP2 & C-1 & C-2 & C-3 \\
\hline Mo & 2,6 & 1,5 & 1,5 & 1,3 & 1,3 & 1,3 & 0,1 & 0,6 & 0,2 & 0,6 & 0,2 & 0,7 & 0,1 & 0 & 0 & 0,1 & 0 & 0 \\
\hline $\mathrm{Cr}$ & 14,7 & 10,4 & 9,2 & 8,6 & 9,1 & 10,3 & 1,6 & 4,0 & 2,1 & 4,8 & 1,6 & 5,0 & 1,3 & 0,3 & 0,3 & 02 & 0,2 & 0,3 \\
\hline $\mathrm{Fe}$ & 41,8 & 58,2 & 61,7 & 63,7 & 62,4 & 58,3 & 87,1 & 79,0 & 79,5 & 76,8 & 85,7 & 75,7 & 87,3 & 91,2 & 90,2 & 90,8 & 90,3 & 90,6 \\
\hline $\mathrm{Ni}$ & 38,7 & 28,7 & 26,1 & 25,1 & 26,1 & 29,4 & 10,0 & 15,3 & 11,5 & 16,8 & 11,4 & 17,2 & 10,2 & 7,6 & 8,1 & 7,6 & 7,9 & 7,7 \\
\hline
\end{tabular}

*indica o primeiro ponto de análise química após a linha de fusão no metal de solda do CP1 (indicado com um círculo azul). C- $2^{1}$ e C- $3^{1}$ representam a região mais próxima do metal de solda. C- $2^{2}$ e C- $3^{2}$ representam pontos da ZPM mais próximos da ZAC. Valores em porcentagem atômica.

No mapa "II" (Figura 7c) a nanodureza da ZAC (425,2 HV) é 6,5\% maior que a ZAC do CP1, igual a ZAC do CP2 e 13,2\% maior que a ZAC do mapa "I" do CP3. O metal de solda tem nanodureza (249,5 HV) 29,6\% maior que o CP1, 11,1\% maior que o CP2, igual ao metal de solda do mapa "I". A nanodureza máxima da zona não misturada é de 369,7 HV e da zona parcialmente misturada tem nanodureza máxima de 434,5 HV.

No mapa "III" (Figura 7c), a região do metal de solda exibe uma nanodureza média de 268,1 HV, a ZAC apresenta nanodureza média 388,2 HV, a zona não misturada possui nanodureza máxima de 369,7 HV e a zona parcialmente misturada tem nanodureza média de 434,5 HV.

A ZPM do mapa I apresenta a menor nanodureza, a menor fração atômica dos elementos químicos Ni e $\mathrm{Cr}$ e a maior fração do elemento Fe (coluna C-1 da Tabela 6), quando comparada as ZPM dos mapas II e III (colunas C- $2^{2}$ e C- $3^{2}$ da Tabela 6). A maior quantidade do elemento químico Ni pode potencializar o efeito de endurecimento por solução sólida na ZPM dos mapas II e III, o que justificaria a maior nanodureza nessas regiões. Contudo, a diferença de $0,4 \%$ do elemento químico $\mathrm{Cr}$ e $1,8 \%$ do elemento $\mathrm{Ni}$ (colunas C-2 e C-3 na ZNM da Tabela 6), não são suficientes para gerar modificações nos valores de nanodureza das ZNM entre os mapas II e III. Mesmo não sendo identificado no trabalho, ressalta-se que o metal de solda pode ser endurecido com a precipitação de fases duras.
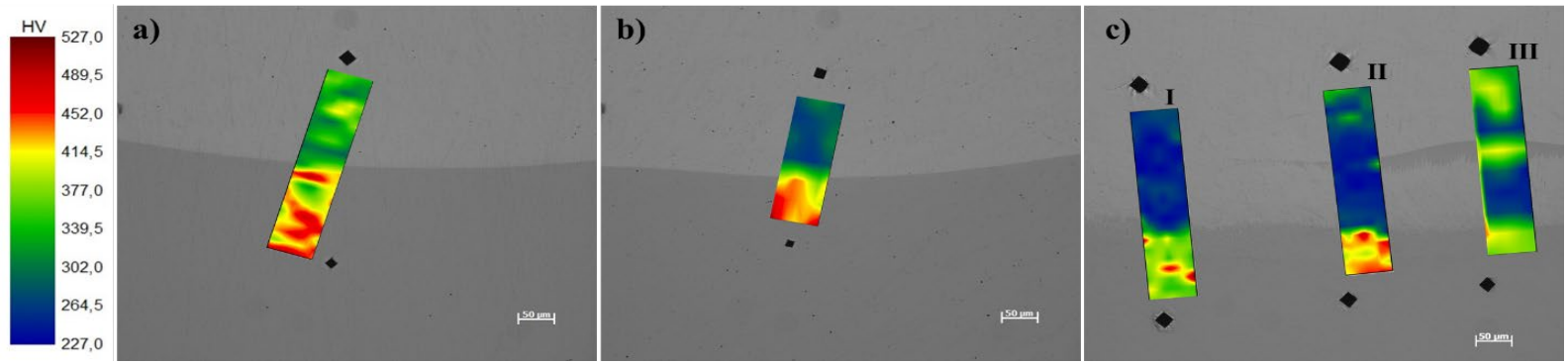

Figura 7. Mapas de nanodureza. (a) CP1-com um cordão de solda; (b) CP2-com dois cordões de solda; (c) CP3-com três cordões de solda.

\subsection{Ensaio de arrancamento}

A tensão de cisalhamento encontrada para o CP1 (um cordão de solda) foi de 165,6 MPa e é 18,3\% maior que o requisito da norma ASTM A265. O CP2 (dois cordões de solda) foi 43,4\% maior quando comparado ao CP1 com uma tensão de cisalhamento de 261,45 MPa e 69,6\% maior que o requisito da norma ASTM A265. O CP3 (três cordões de solda) foi 57,9\% maior quando comparada ao CP1, 10,2\% menor quando comparado ao CP2 e 86,8\% maior que o requisito da norma ASTM A265, obtendo o valor de 261,5 MPa para a tensão de cisalhamento. Todos os corpos de prova atenderam ao requisito da ASTM A265, que para este tipo de material requer tensão mínima de cisalhamento de $140 \mathrm{MPa}$.

Ao comparar os valores de tensão de cisalhamento obtidos e os valores de diluição de cada corpo de prova (Figura 8), observa-se que existe uma relação entre os dois resultados. Conforme se diminui os valores de diluição, há um aumento dos valores de tensão de cisalhamento. Essa afinidade apresenta uma alta relação linear entre os fatores com um valor de $R^{2}$ de 0,9553. A maior diluição pode reduzir a tensão de arrancamento devido a formação de precipitados, a segregação de impurezas, a orientação do grão no limite perpendicular à direção da tensão principal, ou uma combinação destes [26]. 
Comparando as fractografias das amostras rompidas no ensaio de arrancamento, Figura 9, nota-se que as amostras CP1 (um cordão de solda) e CP3 (três cordões de solda) apresentam grande deformação dos dimples no sentido no qual foi aplicada a força e o CP2 (dois cordões de solda) apresenta uma menor quantidade de deformação dos dimples. Contudo, todos as fractografias apresentam características de fratura dúctil.

As trincas em todos os corpos de prova propagaram no metal de solda e não foram evidenciadas trincas secundárias na ZAC. As microanálises químicas realizadas nas regiões destacadas próximas da trinca, apresentam uma alta concentração de Ni e uma baixa concentração de ferro, confirmando que a trinca ocorreu no cordão de solda.

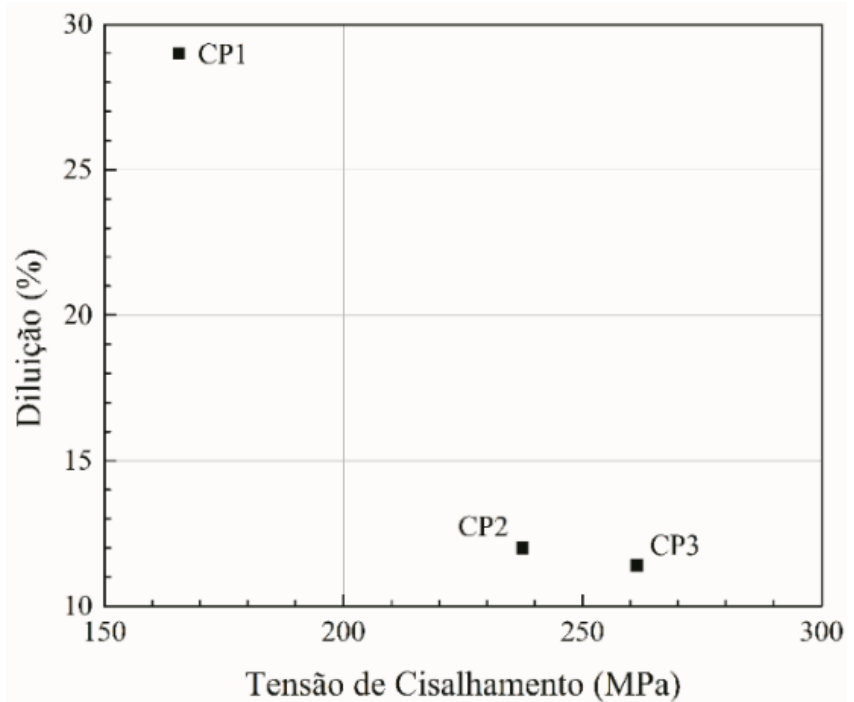

Figura 8. Relação entre diluição e tensão de cisalhamento entre os corpos de prova.
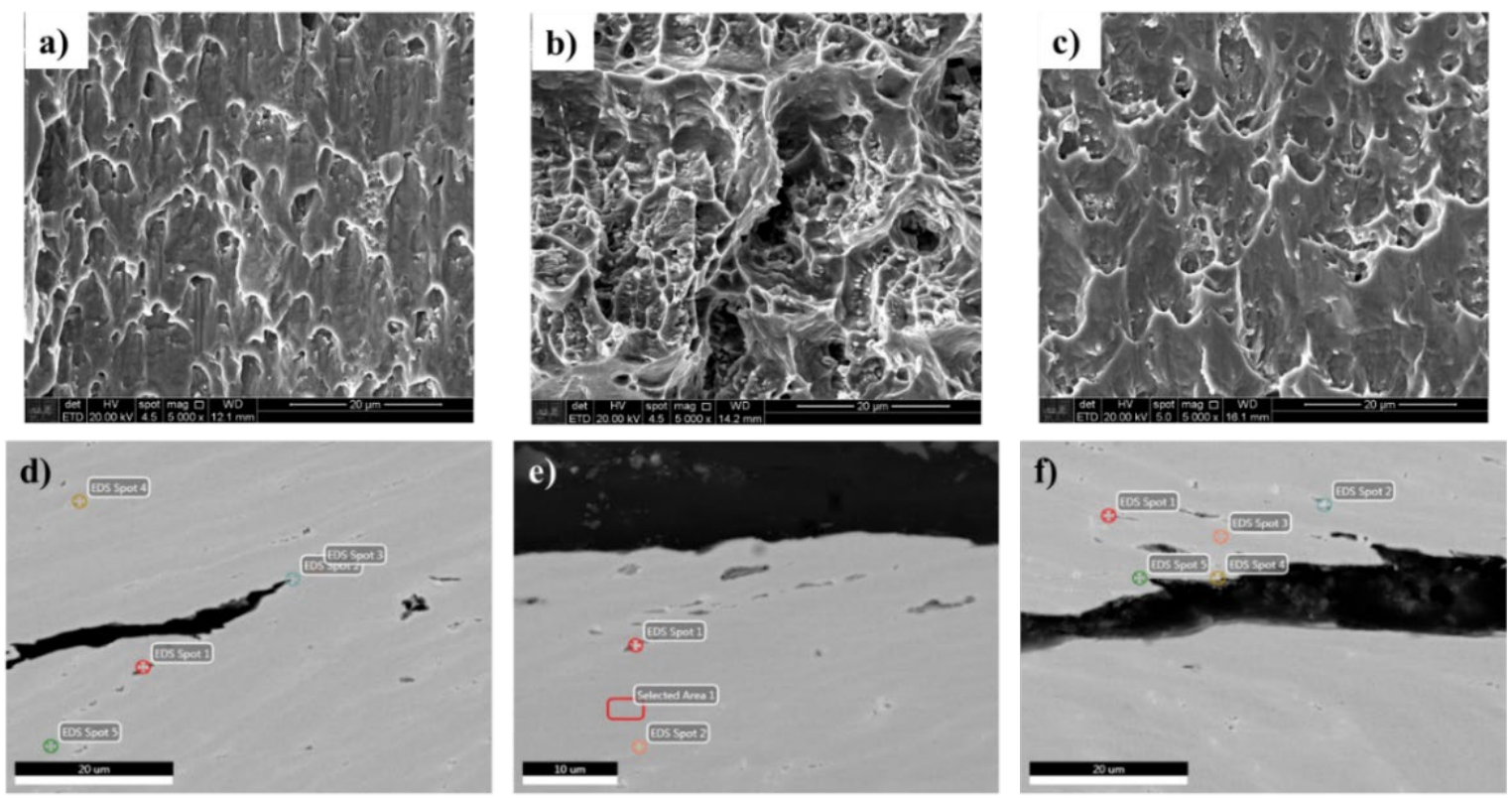

\begin{tabular}{|c|c|c|}
\hline $\begin{array}{c}\text { Elemento } \\
\text { Quimico }\end{array}$ & $\begin{array}{c}\text { Spot 4 } \\
\text { (\% peso) }\end{array}$ & $\begin{array}{c}\text { Spot 5 } \\
\text { (\%peso) }\end{array}$ \\
\hline $\mathrm{Nb}$ & 5,62 & 1,94 \\
\hline $\mathrm{Ti}$ & - & - \\
\hline $\mathrm{Cr}$ & 16,27 & 17,79 \\
\hline $\mathrm{Fe}$ & 25,00 & 24,70 \\
\hline $\mathrm{Ni}$ & 46,83 & 49,31 \\
\hline $\mathrm{Si}$ & 0,13 & 0,26 \\
\hline $\mathrm{Mo}$ & 6,11 & 5,68 \\
\hline
\end{tabular}

\begin{tabular}{|c|c|c|}
\hline $\begin{array}{c}\text { Elemento } \\
\text { Quimico }\end{array}$ & $\begin{array}{c}\text { Spot 1 } \\
\text { \% peso) }\end{array}$ & $\begin{array}{c}\text { Spot 2 } \\
\text { (\%peso) }\end{array}$ \\
\hline $\mathrm{Nb}$ & 49,62 & 10,7 \\
\hline $\mathrm{Ti}$ & 0,94 & - \\
\hline $\mathrm{Cr}$ & 8,57 & 11,95 \\
\hline $\mathrm{Fe}$ & 20,77 & 31,27 \\
\hline $\mathrm{Ni}$ & 20,09 & 38,48 \\
\hline $\mathrm{Si}$ & - & 0,56 \\
\hline $\mathrm{Mo}$ & - & 7,68 \\
\hline
\end{tabular}

\begin{tabular}{|c|c|c|}
\hline $\begin{array}{c}\text { Elemento } \\
\text { Quimico }\end{array}$ & $\begin{array}{c}\text { Spot 1 } \\
\text { \% peso) }\end{array}$ & $\begin{array}{c}\text { Spot 5 } \\
(\% \text { peso) }\end{array}$ \\
\hline $\mathrm{Nb}$ & 12,68 & 1,78 \\
\hline $\mathrm{Ti}$ & 0,41 & - \\
\hline $\mathrm{Cr}$ & 13,54 & 14,58 \\
\hline $\mathrm{Fe}$ & 30,92 & 37,04 \\
\hline $\mathrm{Ni}$ & 36,84 & 42,09 \\
\hline $\mathrm{Si}$ & 0,20 & 0,12 \\
\hline $\mathrm{Mo}$ & 5,41 & 4,38 \\
\hline
\end{tabular}

Figura 9. Imagens em MEV das fractografias das amostras rompidas no ensaio de arrancamento: (a) CP1 (com um cordão de solda); (b) CP2 (com dois cordões de solda); e (c) CP3 (com três cordões de solda). Imagens em MEV da propagação da trinca no sentido transversal e as respectivas microanálises químicas via EDS: (d) CP1 (com um cordão de solda); (e) CP2 (com dois cordões de solda); e (f) CP3 (com três cordões de solda). 


\section{Conclusões}

A análise de EBSD indica que a zona não misturada (ZNM) apresenta uma multiplicidade nas direções cristalográficas similar a ZAC e uma estrutura cristalina cúbica de corpo centrada, similar à ZAC. A zona parcialmente misturada (ZPM) mostra direções cristalográficas mais homogêneas quando comparada com a ZAC e mais heterogêneas quando comparadas ao metal de solda. A ZNM possui uma estrutura cúbica de corpo centrado igual ao restante do metal de solda.

A nanodureza (CP3 mapas I e II) da zona parcialmente misturada (ZPM) é similar a ZAC e até 42,5\% maior que o restante do metal de solda. A nanodureza da zona não misturada (ZNM) é até $14,9 \%$ menor que ZPM até $48,2 \%$ menor que o metal de solda e até $15 \%$ menor que a ZAC.

Todos os corpos de prova tiveram a propagação da trinca no metal de solda e atendem o requisito de 140 MPa mínimo para a tensão de cisalhamento. A diluição apresenta uma correlação com a tensão de cisalhamento. Quanto maior for o valor da diluição do metal de base no cordão de solda, menor será o valor da tensão de cisalhamento.

Não foi possível identificar se o reaquecimento causado pelos demais cordões de solda geraram influência na zona parcialmente misturada (ZPM) e na zona não misturada (ZNM). Como só foi possível identificar essas microrregiões no CP3 (ZPM e ZNM), não há como analisar a influência do reaquecimento dessas microrregiões no CP1 (na ZPM e na ZNM) e no CP2 (apenas na ZNM).

\section{Agradecimentos}

Agradeço ao Programa de Pós-Graduação em Engenharia Metalúrgica do Departamento de Engenharia Metalúrgica e de Materiais da Escola Politécnica da USP e à CAPES por viabilizarem financeiramente este trabalho, com a bolsa de mestrado e os consumíveis utilizados. Por fim, agradecemos ao trabalho em conjunto dos alunos de pós-graduação David Alexander Urbina Leal, ao doutor Daniel Luiz Rodrigues Junior, à técnica Alzira Vicente de Oliveira Corrêa do Instituto de Pesquisas Tecnológicas (IPT), à GMW pela doação dos consumíveis, à White Martins Praxair Arc pela doação do metal de base e dos gases para a realização deste trabalho, e ao laboratório de nanodureza do departamento de Engenharia Mecânica da Escola Politécnica, em especial aos alunos de pós graduação Arnaldo Oliveira Lima e Cassiano Ferreira Bernardes. ANSA e JC agradecem a FAPEAM.

\section{Referências}

[1] Pense AW, Stout RD. Fracture toughness and related characteristics of the cryogenic nickel steels. Canada: International Nickel Co.; 1975.

[2] Nippes EF, Balaguer JP. A study of the weld heat-affected zone toughness of 9\% nickel steel. Welding Research. 1986;(Suppl.): $237-243$.

[3] Soeiro JC Jr. Soldabilidade metalúrgica do aço ASTM A553 Tipo I com 9\% de níquel. São Paulo: Universidade de São Paulo; 2018.

[4] Cipriano Farias FW, Payão JC Fo, Barreto de Azevedo LM. Microstructural and mechanical characterization of the transition zone of $9 \% \mathrm{Ni}$ steel cladded with Ni-based superalloy 625 by GTAW-HW. Metals. 2018;8(12):1-28. http://dx.doi.org/10.3390/met8121007.

[5] Soeiro JC, Rocha DB, Brandi SD. A brief history review of development on API steels welding for pipeline. Soldagem e Inspeção. $2013 ; 18(2)$

[6] Vollmer LW. Hydrogen sulphide corrosion craking of steel. Symposium on Sulfide Stress Corrosion. 1952; 8:326-332.

[7] Pinho Emygdio GZ, Santos de Assis K, Zeemann A, Mattos OR. Behavior of 9Ni steel in the presence of aqueous solutions containing CO2 and H2S. Corrosion. 2017;73(3):303-314. http://dx.doi.org/10.5006/2198.

[8] Silva CC, Afonso CRM, Ramirez AJ, Motta MF, Miranda HC, Farias JP. Aspectos metalurgicos de revestimentos dissimilares com a superliga a base de niquel Inconel 625. Soldagem e Inspeção. 2012;17(3):251-263. http://dx.doi.org/10.1590/S010492242012000300009.

[9] Savage WF, Nippes EF, Szekeres ES. A study of weld interface phenomena in a low alloy steel. Welding Journal. 1976;55(9):260-268.

[10] Solecka M, Kopia A, Radziszewska A, Rutkowski B. Microstructure, microsegregation and nanohardness of CMT clad layers of Ni-base alloy on 16Mo3 steel. Journal of Alloys and Compounds. 2018;751:86-95. http://dx.doi.org/10.1016/j.jallcom.2018.04.102.

[11] Solecka M, Kopia A, Petrzak P, Radziszewska A. Microstructure, chemical and phase composition of clad layers of Inconel 625 and Inconel 686. Archives of Metallurgy and Materials. 2018;63(1):513-518.

[12] Savage WF, Nippes EF, Szekeres ES. Hydrogen induced cold cracking in a low alloy steel. Welding Journal. 1976;55(9):276s-283s.

[13] Baeslack WA, Lippold JC, Savage WF. Unmixed zone formation in austenitic stainless steel weldments. Welding Journal. 1979;58(6):168s$176 s$.

[14] Lippold JC, Savage WF. Solidification of austenitic stainless steel weldments: part 2-the effect of alloy composition on ferrite morphology. Welding Journal. 1980;(2):48s-58s.

[15] Doody T. Intermediate mixed zones in dissimilar metal welds for sour service. Welding Journal. 1992;71(3):55-60. 
[16] Ornath F, Soudry J, Weiss BZ, Minkoff I. Weld Pool Segregation During the Welding of Low Alloy Steels with Austenitic Electrodes Valuable data are developed on the composition at the fusion boundary between austenitic weld metal and ferritic base metal. Welding Journal. 1981;60(11):227s-230s.

[17] Albert SK, Gill TPS, Tyagi SL, Mannan SL, Kulkarni SD, Rodriguez O. Soft zone formation in dissimilar welds between two Cr-Mo steels. Welding Journal. 1997;66(3):135s-142s.

[18] Omar AA. Effects of welding parameters on hard zone formation at dissimilar metal welds. Welding Journal. 1998;67(2):86s-93s.

[19] Rowe MD, Nelson TW, Lippold JC. Hydrogen-induced cracking along the fusion boundary of dissimilar metal welds. Welding Journal. 1999;78(2):31s-37s.

[20] Xu X, Mi G, Chen L, Xiong L, Jiang P, Shao X, et al. Research on microstructures and properties of Inconel 625 coatings obtained by laser cladding with wire. Journal of Alloys and Compounds. 2017;715:362-373. http://dx.doi.org/10.1016/j.jallcom.2017.04.252.

[21] Yang YK, Kou S. Macrosegregation in Al-Si welds made with dissimilar filler metals. Science and Technology of Welding and Joining. 2010;15(1):1-14. http://dx.doi.org/10.1179/136217108X343957.

[22] Mu W, Cai Y, Wang M, Hua X. Microstructure characteristics and properties of fusion boundary in 9\%Ni steel joint filled with Ni-based alloy. Materials Characterization. 2020;165:1-14. http://dx.doi.org/10.1016/j.matchar.2020.110390.

[23] Grong O. Metallurgical modelling of welding. 2nd ed. Boca Raton: CRC Press; 1997.

[24] Monlevade EF. Estudos das transformações morfológicas na decomposição da austenita utilizando um par de difusão Fe-5\%Ni/Fe10\%Ni. São Paulo: Universidade de São Paulo; 2013.

[25] Lippold JC. Welding metallurgy and weldability. New Jersey: John Wiley \& Sons, Inc.; 2014.

[26] DuPont JN, Lippold JC, Kiser SD. Welding metallurgy and weldability of nickel-base alloys. New Jersey: John Wiley \& Sons, Inc.; 2009. p. 440. http://dx.doi.org/10.1002/9780470500262. 